\title{
Sociocultural peculiarities of gender aspect in Russian education and science
}

\author{
Leyla Buniyaminovna Omarova ${ }^{1^{*}}$, Diana Zurabovna Muzashvili ${ }^{2}$, Irina Gennadievna \\ Prokhorova $^{3}$, Natalia Valerievna Savchenko ${ }^{4}$, and Anna Alexandrovna Suchilina ${ }^{5}$ \\ ${ }^{1}$ Financial University at RF Government, Department of Humanitarian Sciences, Moscow, Russia \\ ${ }^{2}$ Financial University at RF Government, Department of Psychology and Human Resources \\ Development, Moscow, Russia \\ ${ }^{3}$ Financial University at RF Government, Sociology Department, Moscow, Russia \\ ${ }^{4}$ Financial University at RF Government, Department of the English Language and Professional \\ Communication, Moscow, Russia \\ ${ }^{5}$ Financial University at RF Government, Department of Political Science, Moscow, Russia
}

\begin{abstract}
Urgency of the problem is conditioned by the fact that under the effect of globalization processes, digital revolution, and transformation of values the present-day society is changing its attitude towards gender division of labor. Gender problem in traditional communities where, on the one hand, new views on the roles of men and women are being formed, and, on the other hand, traditional attitude towards those roles, is being preserved, is of special interest. The objective of the research is to analyze present-day society for revealing the gender asymmetry in different spheres of science and education in Russia. The Russian society that tends to traditional attitude but is unavoidably a part of innovation society, becomes an interesting object for studying the gender aspect in different professional spheres of education and science. A sociocultural approach forms the methodological base of the research that allows us to analyze the current stage of development of the educational and scientific spheres taking into account social and cultural peculiarities of the society, as well as its gender perspective. The study is based on the works that reveal gender issues in modern society in the sphere of education and science, psychology, culture and philosophy. It also presents the analysis of present-day scientific and educational spheres and gender asymmetry occurred under the effect of some or other social or cultural peculiarities.
\end{abstract}

Keywords: education, science, professional sphere, gender gap, culture, social environment, traditions, innovations

\section{Introduction}

Rapid changes in the modern society as a consequence of globalization processes that transform the social platform and values form a new attitude towards a gender aspect in the professional sphere.

\footnotetext{
* Corresponding author: levlaomarova1@gmail.com
} 
Despite some different feminist movements in the $20^{\text {th }}-21^{\text {st }}$ centuries that claimed and defended the women's rights in different spheres of life, many professions remained predominantly men's ones. Moreover, some professional and scientific spheres that emerged with development of digital and informational technologies are immanently assumed to be men's spheres. The percentage of women in sciences related to medical care, in the sphere of social and humanitarian sciences is rather high, but in sciences related to IT, energy, and engineering women are in absolute minority. As to participation of women in large-scale scientific studies, the 'glass ceiling' or 'leaking pipeline' effect is observed. The share of women on the global scale who got bachelor and magister degrees exceeds the share of men and makes $53 \%$, but the share of women with scientific degrees, especially $\mathrm{PhD}$ degrees makes only $43 \%$. As to women dealing with scientific practice, their share does not even reach $30 \%$ ( $28 \%$, to be more exact).

Low percent of women involved in fundamental studies and lack of high positions occupied by women in science despite gender equality observed in all the educational spheres during the latest decades, and even gender asymmetry in favour of women in some spheres makes us investigate the causes of this phenomenon.

The gender balance in science and education is affected by many factors that are both of global and local nature. Economic situation and level of scientific and technological development in individual regions are the basic factors. For example, the share of women-scientists in South-East Europe makes 40\%, whereas in South African countries it is as low as $30 \%$. Social and cultural traditions are another crucial factor. For example, in Arab countries, despite high economic development, the number of women in science is $12 \%$ lower than in European countries, and this number in Japan is three times lower than in Europe.

\section{Methods}

A method of complex social and cultural analysis applied in the course of the study allows us to reveal factors affecting the low share of women at high positions in science and science management boards. The scope of our research is in studying and searching for some possible solutions as in current science education, on the one hand, women in top positions are in need, on the other hand, there are various social, cultural and psychological barriers to female social mobility.

\section{$3 \quad$ Results}

Social studies on the gender aspect in the modern system of education demonstrate a large number of women in the higher education system.

For instance, a famous Harvard astronomer and physicist Edward Charles Pickering employed a group of female scientists who performed boring and unspecialized work. Regardless of the unequal pay and distribution of responsibilities, this work was crucial. Edward Pickering is known to be a greatest scientist who introduced the use of the meridian photometer to measure the magnitude of stars. Whereas female scientists like Annie Jump Cannon, Williamina Fleming, Henrietta Swan Leavitt, Antonia Maury, and Florence Cushman are called Harvard Computers and barely mentioned in the world of science.

This is due to the fact that education nowadays is one of the means of a vertical social lift. It allows a higher level of earnings, but getting a job with such income requires women to demonstrate higher professional level than that of men, i.e., it is more difficult for a 
woman to get that job as an employer makes them prove their professional competence in a certain sphere. This is not conditioned by cultural or social peculiarities only. Psychologically a woman-professional or a scientist in the majority of cases is doubted by employers.

This explains a gender gap in favour of men at managerial positions in science and education.

A present-day manager or a head, and society as a whole, surely, do not agree to Plato [1] or Machiavelli [2] who makes a woman equal to man's property. But the majority who keeps to an archetype where a woman is a supplement that is needed rather than the main thing, is not ready to hand over the reins of power to a woman in any sphere, to say nothing of science.

The number of women-executives of high educational institutions in Russia, for example, is as low as 10\%; among 836 Academicians of the Russian Academy of Sciences there are only 46 women. And this situation persists despite the fact that in 2015 the UNESCO report on science noted that "gender equality $(45-55 \%$ of women among scientific workers) in many regions is a heritage of the former soviet union that included Middle Asia, Baltic countries, East and South-East Europe" [3].

\section{Discussion}

The problem of gender equality in science and education is among the most urgent issues of the modern society. It is a concern of specialists on education science, psychology, and sociology. The objective of the modern society and the scientific community is to reveal problems of a gender misbalance and find the best solutions.

Gender sociology in the Russian science is considered in the works by G.G. Sillaste (2016) [4] who analyzes the gender asymmetry in science and education. G.G. Sillaste gives a detailed characteristic of women and men position in the present-day science and education. The works by N.A. Shvedova, I.O. Maltsev, S.S. Balabanov, E.P. Myasin study the gender asymmetry in natural and humanitarian sciences, the problem of a "glass ceiling", issues related to vertical social lift in the scientific and academic environment.

Some foreign researchers analyze and find the solutions to the same problems. Camille S. Johnson, Pamela K. Smith, Chunlei Wang [5], for example, speculate on the low number of women at the world scientific symposia as the main speakers where they are mainly assistants [5]. Cristina Gimenez Elorriaga, Monike Nicolas [6] in their report at the scientific congress Ciencia technologia y Genero, XI Congreso iberoamericano noted that "despite the progress, the programs, laws and policies that were adopted, noted, implemented and evaluated, and were to contribute to equality of men and women in that sphere at the international level" the number of women in science and engineering in such key spheres as STEM (Science Technology Engineering Mathematics) does not remain in favour of women [6] as women's contribution in the majority of cases remains underestimated or not estimated at all.

Marta du Vall, Marta Majorek [7], Polish researchers of gender problems in the modern European society agree to the fact that "stereotypes on the distribution of roles between women and men historically formed in the public conscience were carried over to the realities of the present-day epoch" [7, 8].

American psychologists Lin Bian, Sarah-Jane Leslie, Andrei Cimpian [9] state that girls even in their childhood tend to believe the similar stereotypes about the impossibility to get the educational level in definite sciences. The scientists say that common stereotypes associate high-level intellectual ability (brilliance, genius, etc.) with men more than women. 
These stereotypes discourage women's pursuit of many prestigious careers; that is, women are underrepresented in fields whose members cherish brilliance (such as physics and philosophy) [9].

The research studies of Murphy, M. C., Steele, C. M., \& Gross, J. J. (Murphy, Steele, Gross, 2007) [10], Leslie, S. J., Cimpian, A., Meyer, M., Freeland, E. (Leslie, Cimpian, Meyer, Freeland, 2015) [11], Guiso, L., Monte, F., Sapienza, P., \& Zingales, L. (Guiso, Monte, Sapienza, Zingales, 2008) [8], Ackerman, P. L., \& Heggestad, E. D. (Ackerman, Heggestad, 1997) [12], Kanagawa, C., Cross, S. E., Markus, H. R. (Kanagawa, Cross, Markus, 2001) [13], Anna Szlavi (A. Szlavi) [14], Nigora Salieva, Ulugbek Saliev (N. Salieva, U. Saliev) [15] aims at destroying the myth of being bad at maths. Based on many social psychology studies and experiments some scientists consider that the stereotypes in some cultural codes may contribute to the formation of false social identity as belonging to particular sex or gender groups.

\section{Conclusion}

Despite the fact that in terms of gender the number of women with higher education in the modern society exceeds that of men, the number of women-scientists and heads of large-scale scientific projects on the global scale decreases. After getting a master's degree a woman is lost for science. This is due to some social, cultural and psychological factors.

Because of cultural or social stereotypes even those who start their scientific career, give it up under certain circumstances.

The society declares publicly about the gender equality, although secretly follows traditional archetypes. Therefore, this problem requires a systematic approach with the change of attitude towards women from different standpoints. That is a global challenge and it has to be solved on a global scale. Gender equality is not only a fundamental human right, but a necessary foundation for a peaceful, prosperous and sustainable world. The Sustainable Development Goals (SDGs) and Global Health of the UN, Goal 4 aims to ensure inclusive and equitable quality education and promote lifelong learning opportunities for all. Moreover, Goal 5 is to achieve gender equality and empower all women and girls [16].

We agree with N.A. Shvedova that gender equality is the primary goal and an important tool for development and a better quality of life. Only it may ensure an economic growth.

\section{References}

1. Plato, The State (ACT, Moscow, 2020)

2. N. Machiavelli, The Prince (EKSMO, Moscow, 2017)

3. C. Hugher, Is the gender gap narrowing in science and engineering? Accessed on: September 25, 2021. [Online]. Available:

https://en.unesco.org/sites/default/files/usr15_is_the_gender_gap_narrowing_in_scienc e_and_engineering_ru.pdf

4. G.G. Sillaste, Gender sociology and Russian reality (Alfa-M, Moscow, 2016)

5. S.J. Camille, K.S. Pamela, W. Chunlei, Person Soc Psy Bul, 43(4), 493-507 (2017). https://doi.org/10.1177/0146167216688213

6. C.G. Elorriaga, M. Nicolas, Impacto de los Premios en Genero, Ciencia y Technologia: del efecto Matilda a la Teoria del Embudo en la creacion del Premio Ada Byron a la 
Mujer Tecnologa de la Universidad de Deusto, in Ciencia technologia y Genero, XI Congreso iberoamericano (2016)

7. M. du Vall, M. Majorek, Aequalitas, 2(1(2)), 2-17 (2013)

8. L. Guiso, F. Monte, P. Sapienza, L. Zingales, Science, 320, 1164-1165 (2008)

9. L. Bian, S-J. Leslie, A. Cimpian, Science, 355, 389-391 (2017)

10. M.C. Murphy, C.M. Steele, J.J. Gross, Psy Sci, 1(18), 879-885 (2007).

DOI: $10.1111 / \mathrm{j} .1467-9280.2007 .01995 . x$

11. S.J. Leslie, A. Cimpian, M. Meyer, E. Freeland, Science, 347, 262-265 (2015). https://doi.org/10.1126/science. 1261375

12. P.L. Ackerman, E.D. Heggestad, Psy Bul, 121, 218-245 (1997). https://doi.org/10.1037//0033-2909.121.2.219

13. C. Kanagawa, S.E. Cross, H.R. Markus, Person Soc Psy Bul, 27, 90-103 (2001). https://doi.org/10.1177/0146167201271008

14. A. Szlavi, J Res Int Edu, 2(2), 26-40 (2020). https://doi.org/10.36427/CEJNTREP.2.2.472

15. N. Salieva, U. Saliev, The Amer J Soc Sci Edu Innov, 3, 292-295 (2021). https://doi.org/10.37547/tajssei/Volume03Issue05-52

16. N.A. Shvedova, Woman Rus Soc, 3/4, 17-30 (2015) 